\title{
Ultrasonography of the Placenta
}

\section{K. VANDENBERGHE}

The in vivo placenta is a different organ from the delivered placenta. In utero the placenta is thicker, more extended and more voluminous; it is usually found to be dome-shaped, but in reality it is quite dynamic because of uterine contractility and flexibility, fetal positioning and movements, and circulation conditions. Compound and realtime ultrasonography enable visualization of these phenomena; once visualized, its location, mensurations and tissue characteristics can be studied; flow studies are also envisaged.

From about eight weeks amenorrhea on, the typical sickle shape of the placenta is present. The placenta is easily recognized as a soft tissue mass occupying a large part of the intra-uterine wall, delineated by a dense echoline of the chorionic plate, and by a rather transsonic zone of the decidualized uterine wall; the villous tissue presents with a homogeneous medium-strong echopattern.

Placental localization proved to be one of the first valuable clinical applications of obstetric echography (9). The factors of uterine movability, flexibility and contractility show the necessity to use uterine, not maternal, points of reference to indicate the exact placental location. The differential growth of the uterine wall, with progressive elongation of the lower, isthmic segment, suffices to explain the increasing distance between the lower placental margin and the internal cervical os in the follow-up of early low placental implantation. There seems to be no need for a new hypothesis of dynamic placental migration (8), and there is certainly no proof for the validity of such hypothesis.

\section{Mensurations}

From the first period of diagnostic ultrasound on, measurements of the thickness of the placenta have been undertaken (6). Because of its dome shape and shape changes, it appears much more difficult to measure accurately the placental volume or implantation area. For tridimensional estimations two methods are available : $1^{\circ}$ )integration of serial sections ( 1 , 12 ) and $\left.2^{\circ}\right)$ calculations with approximative formulae $(5,13)$. The first method is undoubtedly the most accurate, and is generally used as a reference to test the accuracy of other methods; technical facilities, such as light pen and digital computer, will enable to apply this approach on a more routine base in the near future. We used the formula-method (uterus = sphere or ellipsoid; placenta = segment of sphere or ellipsoid), which in general gives somewhat lower values than the expected (factor of excentricity). The formula-method is only sufficiently reproducible in the fully anterior and some posterior placentas.

In a cross-sectional study in 180 normal primi- and multigravidae, the placental implantation area increased from about $50 \mathrm{~cm}^{2}$ at 12 weeks to more than $400 \mathrm{~cm}^{2}$ near term. Comparing the placental bed areas with the total intra-uterine surface available at any given moment, a steady decrease was noted from about $40 \%$ at 12 weeks to $30 \%$ or less at 40 weeks. From these data it is evident that although the placenta increases its implantation area more than eight times in absolute terms, it does not exceed the original borders of its placental bed, but follows the expansion of the uterine cavity. The relatively more pronounced elongation

\author{
0300-5577/81/0091-0020\$2.00 \\ Copyright by Walter de Gruyter \& Co.
}


of the lower uterine segment, which is rarely covered by plạcenta, can explain the decreasing relation.

The placental volume increased from about $100 \mathrm{~cm}^{3}$ at 12 weeks to $600 \mathrm{~cm}^{3}$ near term. In the growth curves with the mean values of placental volume and implantation area the S-shaped pattern, typical for growth phenomena, can be recognized. After 34-35 weeks the growth rate is decreasing markedly, and in some cases becoming negative. Some authors however, found a zero or negative growth in the last five weeks of pregnancy in the majority of the studied population $(1,12)$. Individual longitudinal serial measurements can be expected to give additional information (7).

In order to find clinical applications feto-placental correlations have to be established, and ultrasonic measurements of the placenta have to be accurate, reproducible and feasible. Although the fresh placenta at delivery and even more so after fixation, is a different organ from the in vivo placenta, the neonatal-placental correlations can give valuable information. Literature data on this subject have been reviewed extensively by the Denver group (10). In a series of 140 delivered placentas, measured in a standardized way, we found the following correlations between neonatal weight and placental thickness, matemal surface area and volume respectively : $\mathrm{R}=0,120,0,532$ and 0,714 .

Placental measurements are still considered too indirect to influence clinical decisions, but in extreme stiuations they can indicate some inherent fetal growth problems (as e.g. chromosomal anomalies) or some fetal diseases (as e.g. Rhesus isoimmunization).

\section{Tissue Characteristics}

Tissue characterization has already some important clinical applications as in placental abruption, molar pregnancy, placental chorioangioma, and choriocarcinoma invasion in the uterine wall. With optimal grey-scaling, better focusing and higher frequencies, tissue characterization in the placenta itself has become feasible.

In the third trimester placenta sonodensifications and transsonic areas are often observed $(2,14)$. In order to quantify the normal incidence of these changes a cross-sectional study has been performed in 204 normal single pregnancies (primi- and plurigravidae) between 21 and 40 weeks. Subchorionic transsonic areas are seen incidentally (about $10 \%$ ) over the whole period. Parenchymatous transsonic areas are often present (5\%), but tend to be more frequent near term (up to $25 \%$ ), or are identified more easily by becoming larger. Sonodensifications are rarely observed before the third trimester; we call minor densifications those occurring only marginally or locally in the basal plate, and major densification where the whole basal plate and also very often the septa are involved. At 26-28 weeks in about $5 \%$ of pregnancies minor densifications where observed; their incidence and dimensions increase steadily to be found in about $75 \%$ of pregnancies near term ( $50 \%$ major and $25 \%$ minor). These findings will be applied as reference to study the echographic placental changes in disturbances of fetal growth and in matemal pregnancy disorders.

In selected placentas with specific antenatal ultrasonic characteristics and in some placentas with macroscopic lesions observed after delivery we have performed waterbathscanning and histological studies of selected 
areas. Subchorionic transsonic areas generally correspond with massive subchorial thrombosis. The parenchymatous transsonic areas seem to correspond with septal cysts, Kline's haemorrhages or perivillous fibrin deposition; generally these entities can not be differentiated ultrasonographically. The sonodensifications in the basal plate and in the septa correspond to multilayered fibrinoid deposits mixed with decidual tissue; they can mostly be differentiated from calcification (shadowing, distribution). Gross lesions such as fresh thrombi and massive perivillous fibrin deposition appear as large transsonic areas; fresh and old infarctions can hardly be differentiated from normal villous tissue; they appear to be slightly less echogenic.

The significance of these changes is still a matter of debate. The changes in the basal plate, in the subchorionic region and intraplacentally are often - rather vaguely - referred to as an aging process; they have been correlated to fetal maturation by the Yale group (4). Many localized gross lesions are of relatively limited clinical importance $(3,11)$; however, some more extended or generalized lesions might be clinically relevant, and are echographically detectable.

Acknowledgements : The author is indebted to Dr. F. DE WOLF, ob.-gyn., $\bar{M} \bar{r} \bar{A}$. A $\bar{U} \bar{B} \bar{R} \bar{T}$, med. phys. and Dr. P. GODDEERIS, path., for their assistance in different parts of the study.

References

1. BLEKER O.P., G.J. KLOOSTERMAN, et al. : The volumetric growth of the human placenta : a longitudinal ultrasonic study. Am. J. Obst. Gyn., 127 (1977), 657.

2. FISHER C.C., W. GARRETT, G. KOSSOFF : Placental aging monitored by gray scale echography. Am. J. Obst. Gyn. 124 (1976), 483.

3. FOX H. : Pathology of the placenta. Saunders, London, 1978, 141.

4. GRANNUM P.A.T., R.L. BERKOWITZ, J.C. HOBBINS : The ultrasonic changes in the maturing placenta and their relation to fetal pulmonic maturity. Am. J. Obst. Gyn. 133 (1979), 915.

5. HELLMAN, L.M., M. KOBAYASHI, et al. : Ultrasonic studies on the volumetric growth of the human placenta. Am. J. Obst. Gyn., 108 (1970), 740.

6. HOLLAENDER H.J., H. MAST : Intrauterine Dickenmessungen der Plazenta mittels Ultraschalls bei normaler Schangerschaften und bei Rh-Inkompatibilität. Geburtsh. Frauenheilk. 28 (1968), 662.

7. HOOGLAND H. : personal communication.

8. KING D.L. : Placental migration demonstrated by ultrasonography. A hypothesis of dynamic placentation. Rad., 109 (1973), 167.

9. KRATOCHWIL A. : Placentography. In : "Handbook of Clinical Ultrasound", et. M. DE VLIEGER et al. Wiley Medical, New York, 1978, 175.

10. MOLTENI R.A., S.J. STYS, F.C. BATTAGLIA : Relationship of fetal and placental weight in human beings. J. Reprod. Med., 21 (1978), 327.

11. SPIRT B.A., E.H. KAGAN, R.M. ROZANSKI : Sonolucent areas in the placenta : sonographic and pathologic correlation. Am. J. Roentg. 131 (1978), 961.

12. TERINDE R., H.G. BENDER, et al. : Biometrie der Plazenta. In : "Ultraschalldiagnostik", Ed. A. KRATOCHWIL \& REINOLD, Thieme, Stuttgart, $1978,85$.

13. VANDENBERGHE K. : Ultrasonic study on the growth of the human placental implantation area in the second trimester of pregnancy. In : " Ultrasound in Medicine. Vol. 3 A. Clinical Aspects". Ed. D. WHITE \& R.E. BROWN. Plenum, New York, 1977, 645.

14. WINSBERG F. : Echographic changes with placental aging. J. Clin. Ultras. 1 (1973), 52.

K. Vandenberghe, M.D.

Dept.Obstet.Akademisch Ziekenhuis

Sint Rafael Univ.

B-3000 Leuven/Belgium 